\section{One step multifunctional micropatterning of surfaces using asymmetric glow discharge plasma polymerization $\dagger$}

\author{
Donna J. Menzies, ${ }^{a b}$ Thomas Gengenbach, ${ }^{a}$ John S. Forsythe, ${ }^{b}$ Nick Birbilis, ${ }^{b}$ \\ Graham Johnson, ${ }^{a}$ Christine Charles, ${ }^{c}$ Gail McFarland, ${ }^{a}$ Richard J. Williams, ${ }^{a}$ Celesta Fong, ${ }^{a}$ \\ Patrick Leech, ${ }^{a}$ Keith McLean ${ }^{a}$ and Benjamin W. Muir ${ }^{* a}$
}

Received 9th September 2011, Accepted 12th December 2011

DOI: $10.1039 / \mathrm{c} 2 \mathrm{cc} 15578 \mathrm{~h}$

Micropatterning of surfaces with varying chemical, physical and topographical properties usually requires a number of fabrication steps. Herein, we describe a micropatterning technique based on plasma enhanced chemical vapour deposition (PECVD) that deposits both protein resistant and protein repellent surface chemistries in a single step. The resulting multifunctional, selective surface chemistries are capable of spatially controlled protein adhesion, geometric confinement of cells and the site specific confinement of enzyme mediated peptide self-assembly.

The generation of regular arrays of multiple polymer surface chemistries or features on a surface is routinely used in a number of research fields. ${ }^{1-4}$ Polymer micropatterning techniques generally require a number of steps to produce the desired chemical features, for example photochemical ${ }^{5}$ and lithographic ${ }^{6}$ techniques. $^{6,7}$ However, with the exception of a small number of emerging patterning techniques, ${ }^{8}$ these methods require further chemical derivatization for optimal functionality. ${ }^{8,9}$ The novel technique reported here is based on PECVD and is the first example of a substrate independent, solvent free, one-step process that allows the generation of stable multifunctional micropatterns. During the deposition process, both low protein fouling and high fouling chemically patterned features are deposited simultaneously. PECVD enables the modification of various substrate materials ${ }^{10,11}$ and is scalable for use in sterile environments. ${ }^{12}$ Existing plasma based patterning methods such as etching, ${ }^{13}$ plasma lithography, ${ }^{11}$ and microplasmas ${ }^{11,14}$ currently require numerous production steps for use in biological applications where surface passivation and activation is necessary.

The key innovation of PIPET is the use of a patterned upper electrode (Fig. 1a and $\mathrm{S} 1 \dagger$ ) to produce an asymmetric glow discharge above a substrate. It is important to note that this is

${ }^{a}$ CSIRO, Materials Science and Engineering, VIC 3169, Australia. E-mail:ben.muir@csiro.au

${ }^{b}$ Monash University, Dept of Materials Engineering, VIC 3800, Australia

${ }^{c}$ Australian National University, Research School of Physics and Engineering, ACT 0200, Australia

$\dagger$ Electronic supplementary information (ESI) available: Experimental, schematic of the reactor configuration, XPS surface characterization, detailed information related to enzyme mediated self assembling peptides and modeling of the plasma discharge and acknowledgments. See DOI: $10.1039 / \mathrm{c} 2 \mathrm{cc} 15578 \mathrm{~h}$ not a masking technique. The bulk plasma glow discharge and sheath below the patterned electrode vary spatially, resulting in variation to the fragmentation of the monomer being polymerized which affects the chemical structure of the resulting plasma polymer film.

The versatility of this technique is illustrated via the controlled adhesion of proteins, geometric confinement of cells and the spatial confinement of peptide self-assembly. The performance of biomaterial devices is dependent on their ability to resist or control protein and cell adhesion. ${ }^{15,16}$ The monomer diethylene glycol dimethyl ether (DG) was utilized in this work as it contains ether units which form the backbone of poly(ethylene glycol) (PEG) molecules. ${ }^{17}$ The ether functionality of PEG polymers is critical to their low-fouling nature. ${ }^{18}$ The use of PIPET with DG, provides patterned surfaces with regions of both high ether (PEG-like) and low ether (non PEG-like) chemistries (Fig. 1b). 'Non-PEG-like' chemistries occur directly under the holes of the patterned electrode which is attributable to greater monomer fragmentation in this region. The 'PEGlike' character of the surface increases radially from the centre of the patterned features.

The size, thickness and shape of the patterned features can be varied by manipulation of the upper electrode geometry and PECVD conditions (Fig. 1c). The increased thickness of the films within the centre of the patterned shapes was confirmed via analysis with optical profilometry (Fig. 1d). The elevated features are approximately $200 \mathrm{~nm}$ above the surrounding PEG-like regions which are $60 \mathrm{~nm}$ in thickness, when using electrode patterned features $1 \mathrm{~mm}$ in size. Grazing incidence Fourier Transform Infra-Red (giFTIR) microspectroscopy and time-of-flight secondary ion mass spectroscopy (ToF-SIMS) was used to analyze patterned circles. Chemical maps (Fig. 2a-c) show a higher carbonyl and lower ether content within the circle compared with the surrounding PEG-like film. This suggests that the plasma discharge and monomer fragmentation is more energetic in this region. The presence of carbonyl functionalities originates from bond scission of the monomer and post oxidation reactions.

Modeling of the plasma sheath physics using argon cross sections further validates these findings (see ESI $\dagger$ ). Plasma sheaths are regions where charge separation can occur and strong electron and ion density gradients are present. The model estimated the 
a
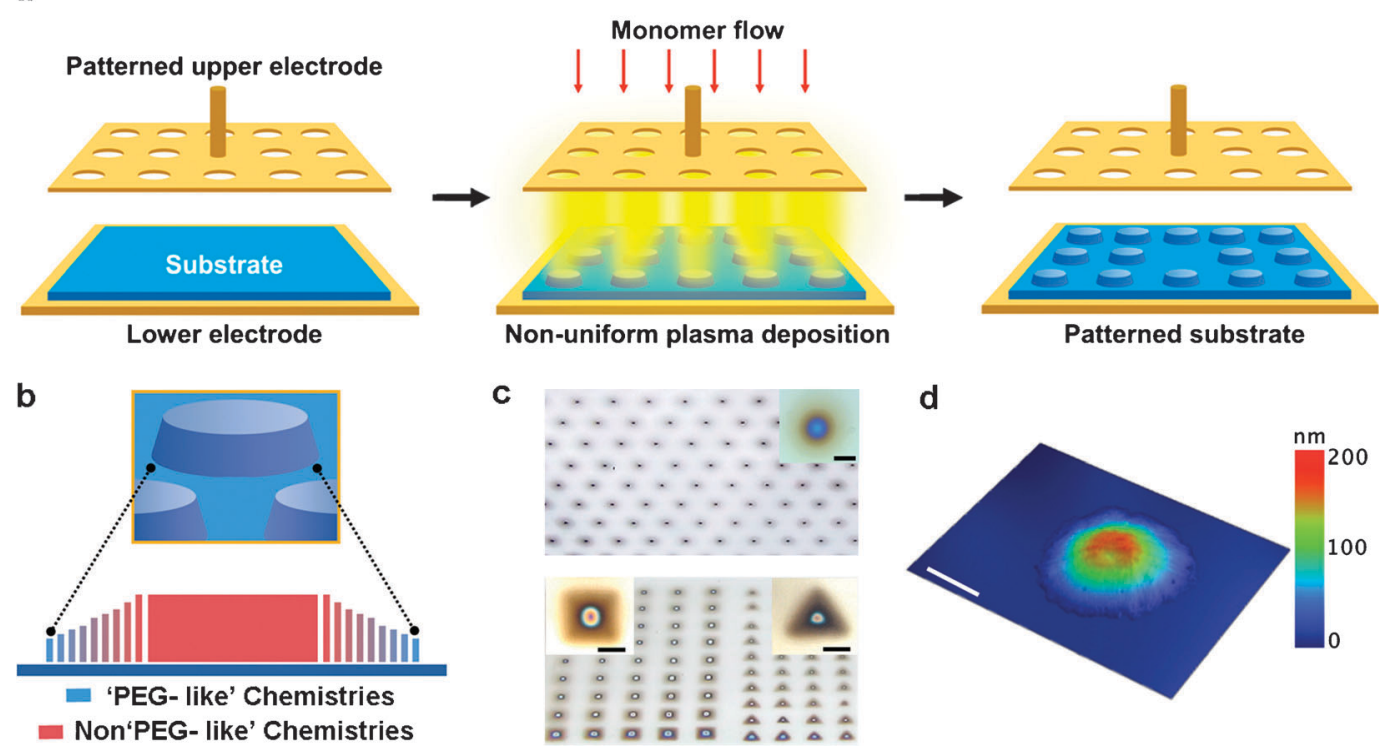

C

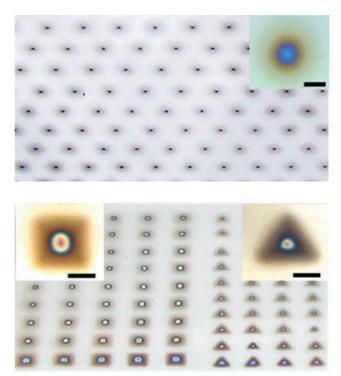

d

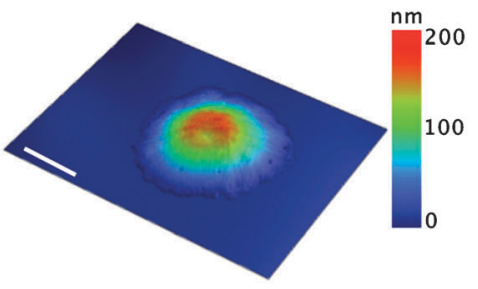

Fig. 1 (a) Schematic of the PIPET technique whereby a substrate material to be coated is placed below a patterned upper electrode and a non-uniform plasma is generated in the presence of gaseous monomer (b) resulting plasma polymer film chemistry variation across a patterned spot. Within a spot the chemistry is less 'PEG-like' compared to the surrounding film. (c) Optical microscopy images of patterned surfaces on silicon wafers (scale bars are $200 \mu \mathrm{m}$ ). The colors inside the elevated features arise from interference of reflected light between the upper and lower film boundaries. Lighter areas in the optical images correlate with thinner 'PEG-like' film chemistries. (d) Optical profilometry image across a spot (scale bar is $200 \mu \mathrm{m}$ ).
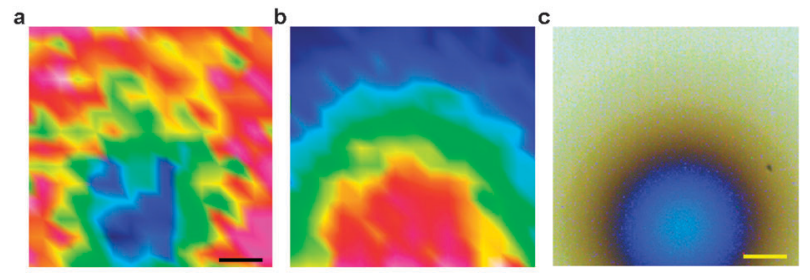

d
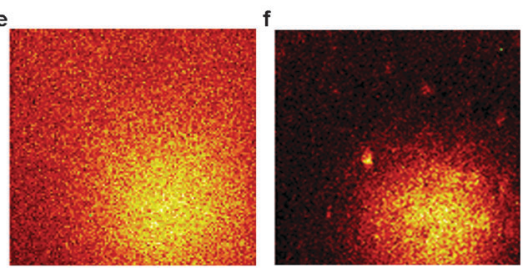

Fig. 2 (a-b) Synchrotron giFTIR plots of the intensity of ether and carbonyl stretches across a spot (high intensity in red and low intensity in blue) on glass, (c) Optical microscopy image of the spot, (d-e) ToFSIMS intensity plots of characteristic ethylene glycol related fragments $\left(\mathrm{C}_{3} \mathrm{H}_{7} \mathrm{O}^{+} \mathrm{C}_{3} \mathrm{H}_{6} \mathrm{O}^{+}, \mathrm{C}_{3} \mathrm{H}_{5} \mathrm{O}_{2}{ }^{+}, \mathrm{C}_{4} \mathrm{H}_{9} \mathrm{O}^{+}, \mathrm{C}_{4} \mathrm{H}_{6} \mathrm{O}_{2}{ }^{+}, \mathrm{C}_{5} \mathrm{H}_{10} \mathrm{O}^{+}\right.$, $\left.\mathrm{C}_{5} \mathrm{H}_{11} \mathrm{O}_{2}{ }^{+}\right)$and hydrocarbon fragments $\left(\mathrm{C}_{4} \mathrm{H}_{9}{ }^{+}, \mathrm{C}_{5} \mathrm{H}_{5}{ }^{+}, \mathrm{C}_{6} \mathrm{H}_{5}{ }^{+}\right.$, $\mathrm{C}_{7} \mathrm{H}_{7}{ }^{+}$) from a PIPET spot, (f) ToF-SIMS intensity plots of nitrogen containing fragments $\left(\mathrm{C}_{5} \mathrm{H}_{5} \mathrm{~N}^{+}, \mathrm{C}_{3} \mathrm{H}_{8} \mathrm{~N}^{+}, \mathrm{C}_{5} \mathrm{H}_{10} \mathrm{~N}^{+}, \mathrm{C}_{5} \mathrm{H}_{12} \mathrm{~N}^{+}\right)$after incubation of a PIPET spot with protein (BSA). High intensity is shown in yellow and low intensity in black. Scale bars represent $100 \mu \mathrm{m}$.

main plasma parameters for comparison with the inter-electrode distance and the patterned hole size (ESI, Table 1†). The Debye length was calculated to be of the order of $100 \mu \mathrm{m}$ which is comparable to the hole size in the upper electrode. This represents a possible limit to the pattern fidelity achievable via this technique of around $100 \mu \mathrm{m}$.

To demonstrate the utility of PIPET in biomedical research we proposed that it should be possible to produce site-specific 'islands' for the containment of protein immobilization, cell proliferation and enzyme assisted self-assembly in a microarray format. Imaging ToF-SIMS was used to map the surface chemistries before and after incubation with bovine serum albumin (BSA) (Fig. 2d). Collective images of positive ethylene glycol related ion fragments commonly reported in PEG-like materials ${ }^{19}$ are shown in Fig. $2 d$ and hydrocarbon ion fragments in Fig. 2e for a surface prior to incubation with BSA. Strong image contrast and good pattern fidelity is observed for all of the ions, with higher concentrations of hydrocarbon fragments being localized in the centre of the circle. More ethylene glycol related or PEG-like ion fragments are observed in the surrounding film. BSA adsorption was strongly retained within the centre of the circle, as indicated by significantly more nitrogen containing ions (Fig. 2f) in these regions. X-ray Photoelectron Spectroscopy (XPS) confirmed the spatial variation of surface chemistries (Fig. S2†).

In our second example we demonstrate the preferential confinement of an adherent HeLa cell line. Optical images of the patterns used to confine cell growth are shown in Fig. 3a and $b$ for a planar array of HeLa cells, in which individual cells attach and spread in the centre of the patterns. The 'PEG-like' regions support minimal cell attachment. The long term stability and robustness under physiological conditions of such patterns is a key performance characteristic. To exemplify the robustness of the PIPET films, cells were incubated on circular patterns for 1 and 7 days (Fig. 3c-d). After 7 days culture the cells remain constrained within the patterned boundary. The surrounding PEG-like regions of the film retained its biological inertness; although a small number of cells were observed initially, these were not viable after several days.

For microarray applications, an arrayed protein must remain functional. In order to explore the potential of PIPET for 
a

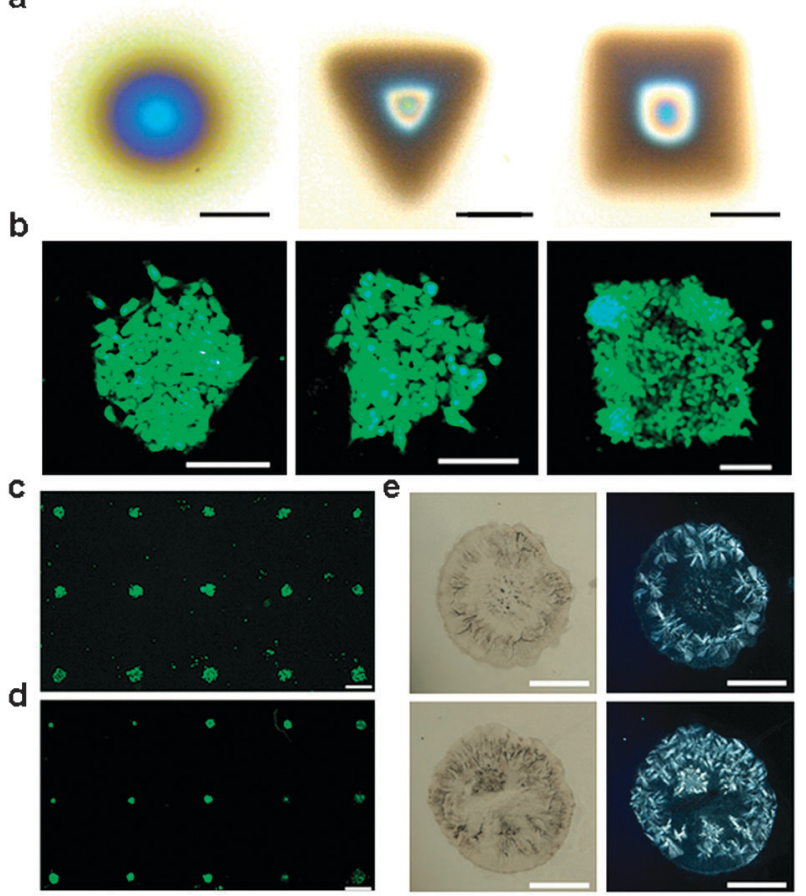

Fig. 3 (a) Optical images of circular, triangular and square patterns generated via PIPET (scale bar $200 \mu \mathrm{m}$ ). (b) Fluorescent images of spatially confined HeLa cells after $24 \mathrm{~h}$ incubation. (Scale bars $100 \mu \mathrm{m}$ ).

(c) HeLa cell attachment across array of spotted patterns after 1 and (d) 7 days (scale bars $250 \mu \mathrm{m}$ ). (e) Bright field (L) and cross-polarized (R) images of the dried, enzyme assisted self-assembled hydrogel formed by constrained enzyme adsorption on the patterns (scale bars $200 \mu \mathrm{m}$ ).

microfabrication, we utilized a system in which a localized enzyme was used to direct the self-assembly of a peptide hydrogel. ${ }^{20}$ The formation of the self-assembling peptide was catalyzed by a proteolytic enzyme and the self-assembly process occurred at the site of enzyme activity (Fig. S3 $\dagger$ ). When the solution of peptide reactants is added, the selfassembly occurs in the vicinity of the enzyme adsorbed in the centre of the patterned circles (Fig. 3e). Spots of hydrogel were observed around $500 \mu \mathrm{m}$ in diameter, suggesting the enzymes are localized which yield nucleation sites, and the hydrogel 'grows' to cover an area greater than the spot of enzyme during the self-assembly.

The presence of the self-assembled, peptide $\beta$-sheets were validated as birefringence (Fig. 3e). We envisage that this technique could be used to form complex patterns of selfassembled peptide hydrogels or enzyme arrays for fabrication, tissue culture and sensing with potential applications in cell culture, ${ }^{21}$ nanoelectronics, and signaling.
We have described a new approach for the generation of substrate independent, multifunctional, patterned surface chemistries that are cell and protein resistant/adherent in a single step. The patterning technique is extremely versatile, tunable, solvent free and scalable. We have demonstrated the broad utility of this strategy through the controlled adhesion of proteins, confinement of HeLa cells and enzyme-assisted peptide self-assembly. The method enables the production of various geometrical shapes and micropattern properties to be deposited with good spatial and chemical fidelity. This multifunctional micropatterning technique has broad applicability in the fields of cell biology, tissue engineering and biomedical science.

\section{Notes and references}

1 C. S. Chen, M. Mrksich, S. Huang, G. M. Whitesides and D. E. Ingber, Science, 1997, 276, 1425-1428.

2 G. C. Engelmayr, M. Cheng, C. J. Bettinger, J. T. Borenstein, R. Langer and L. E. Freed, Nat. Mater., 2008, 7, 1003-1010.

3 M. L. Renak, G. C. Bazan and D. Roitman, Adv. Mater., 1997, 9, 392-395.

4 H. Tavana, A. Jovic, B. Mosadegh, Q. Y. Lee, X. Liu, K. E. Luker, G. D. Luker, S. J. Weiss and S. Takayama, Nat. Mater., 2009, 8, 736-741.

5 M. S. Hahn, L. J. Taite, J. J. Moon, M. C. Rowland, K. A. Ruffino and J. L. West, Biomaterials, 2006, 27, 2519-2524.

6 R. S. Kane, S. Takayama, E. Ostuni, D. E. Ingber and G. M. Whitesides, Biomaterials, 1999, 20, 2363-2376.

7 R. D. Piner, J. Zhu, F. Xu, S. H. Hong and C. A. Mirkin, Science, 1999, 283, 661-663.

8 R. Klajn, M. Fialkowski, I. T. Bensemann, A. Bitner, C. J. Campbell, K. Bishop, S. Smoukov and B. A. Grzybowski, Nat. Mater., 2004, 3, 729-735.

9 F. Bretagnol, O. Kylian, M. Hasiwa, L. Ceriotti, H. Rauscher, G. Ceccone, D. Gilliland, P. Colpo and F. Rossi, Sens. Actuators, B, 2007, 123, 283-292.

10 T. Desmet, R. Morent, N. De Geyter, C. Leys, E. Schacht and P. Dubruel, Biomacromolecules, 2009, 10, 2351-2378.

11 G. S. Malkov, I. T. Martin, W. B. Schwisow, J. P. Chandler, B. T. Wickes, L. J. Gamble, D. G. Castner and E. R. Fisher, Plasma Processes Polym., 2008, 5, 129-145.

12 Y. N. Xia and G. M. Whitesides, Annu. Rev. Mater. Sci., 1998, 28 , $153-184$

13 P. K. Chu, J. Y. Chen, L. P. Wang and N. Huang, Mater. Sci. Eng., $R, 2002,36,143-206$.

14 M. Leduc, S. Coulombe and R. L. Leask, IEEE Trans. Plasma Sci., 2009, 37, 927-933.

15 R. G. Chapman, E. Ostuni, L. Yan and G. M. Whitesides, Langmuir, 2000, 16, 6927-6936.

16 B. Muir, A. Fairbrother, T. Gengenbach, F. Rovere, M. Abdo, K. McLean and P. Hartley, Adv. Mater., 2006, 18, 3079-3082.

17 J. Israelachvili, Proc. Natl. Acad. Sci. U. S. A., 1997, 94, 8378-8379.

18 R. A. Latour, J. Biomed. Mater. Res., Part A, 2006, 78A, 843-854.

19 F. Brétagnol, L. Ceriotti, M. Lejeune, A. Papadopoulou-Bouraoui, M. Hasiwa, D. Gilliland, G. Ceccone, P. Colpo and F. Rossi, Plasma Processes Polym., 2006, 3, 30-38.

20 R. J. Williams, A. M. Smith, R. Collins, N. Hodson, A. K. Das and R. V. Ulijn, Nat. Nanotechnol., 2009, 4, 19-24.

21 V. Jayawarna, M. Ali, T. A. Jowitt, A. E. Miller, A. Saiani, J. E. Gough and R. V. Ulijn, Adv. Mater., 2006, 18, 611-614. 